\title{
INFLUENCE OF THERMAL HISTORY BEFORE HOT WORKING ON FLOW STRESS OF MULTIPHASE STEEL
}

\author{
Shunsuke SASAKI, Tatsuro KATSUMURA
}

JFE Steel Corporation, Aichi, Japan, shu-sasaki@ife-steel.co.jp

https://doi.org/10.37904/metal.2019.697

\begin{abstract}
The influence of the cooling rate immediately before hot working on the flow stress and microstructure of $\delta$ ferrite-austenite duplex stainless steel $(25 \% \mathrm{Cr}$ duplex stainless steel) was investigated by a hot compression test at $1,000-1,200{ }^{\circ} \mathrm{C}$ with various strain rates $\left(0.1\right.$ to $\left.10.0 \mathrm{~s}^{-1}\right)$. In spite of the fact that the compression temperature was the same, the condition of rapid cooling immediately before the hot compression test greatly reduced the maximum flow stress $\sigma_{\max }$ and work-hardening coefficient $n$ values. In addition, the stable stress at a slow strain rate of $0.1 \mathrm{~s}^{-1}$ under the rapid cooling condition gradually increased with increasing compression strain. The microstructure just after the compression test was investigated by EBSD (Electron Back Scatter Diffraction Patterns). As a result of a detailed crystal orientation analysis, it was found that supercooled $\delta$ ferrite produced by rapid cooling immediately before the hot compression test influenced the decrease in $\sigma_{\max }$ and $n$. Furthermore, a slow strain rate condition promoted the strain induced austenite phase transformation from the supercooled $\delta$ ferrite phase during the hot compression test, and because the increased austenite phase during the hot compression test is harder than the $\delta$ ferrite phase, stable stress gradually increased together with progress of the austenite transformation.
\end{abstract}

Keywords: Duplex stainless steel, flow stress, hot compression test

\section{INTRODUCTION}

To predict the working load and strain distibution in hot rolling and forging processes, the measurement accuracy of flow stress is important. In general, a hot uniaxial compression test is selected to measure flow stress, and the working temperature and strain rate are changed in order to consider recovery during hot working. However, the results of hot workability shown in previous studies only considered the condition of holding at a uniform holding temperature; in other words, previous studies did not consider the temperature drop history from the initial heating temperature to the working temperature. At actual production lines, change of the cooling rate just before hot working occurs naturally during working. This study investigated the influence of accelerated cooling immediately before hot working on the material microstructure and hot strength.

Duplex stainless steel was chosen as the material for research because it has a dual phase structure at the hot working temperature and the phase balance changes continuously and widely accompanying changes in temperature. In other words, since the phase balance of duplex stainless steel is thought to react sensitively to accelerated cooling immediately before hot working, this material was considered suitable for research investigating the influence of the cooling rate immediately before hot working. The flow stress of duplex stainless steel has been reported in several papers and the technical literature. Y. Yang [1], A. Momeni [2], W. G. Fan [3], H. Farnoush [4] and R. J. Kearns [5] measured the hot flow stress of $25 \% \mathrm{Cr}$ stainless steel in the $800-1,200{ }^{\circ} \mathrm{C}$ temperature region at strain rates from 0.001 to $1.0 \mathrm{~s}^{-1}$ by a uniaxial compression test in order to propose approximate fitting equations. To measure the deformation resistance until the high strain range, S.Spigarelli [6], J. A. Moreir [7] and M. Barteri [8] conducted a hot torsion test and successfully proposed an approximate expression. However, no results concerning the effect of the thermal history immediately before hot working on hot workability could be found in the literature. Therefore, in this study, a hot uniaxial compression test of duplex stainless steel was carried out using greatly different cooling rates $(0.1$ and 
$30.0^{\circ} \mathrm{C} / \mathrm{s}$ ) immediately before hot working in order to determine the effect of the cooling rate immediately before hot working on change of the hot flow stress and microstructure.

\section{EXPERIMENTAL CONDITIONS}

Table 1 shows the chemical composition of the $25 \% \mathrm{Cr}$ duplex stainless steel. Figure 1 shows the equilibrium diagram of the test material, and Figure 2 shows the conditions of the uniaxial hot compression test. The initial heating temperature was set uniformly to $1,250^{\circ} \mathrm{C}$, and the hot working temperature was in the range of $1,000{ }^{\circ} \mathrm{C}$ to $1,200{ }^{\circ} \mathrm{C}$. The ratio of the $\delta$ ferrite and austenite phases changed continuously during hot working. The specimen shape was cylindrical with diameter $8 \mathrm{~mm}$ and length $12 \mathrm{~mm}$, and the specimen temperature was controlled by induction heating and $\mathrm{N}_{2}$ gas cooling. The strain rates were $0.1,1.0$ and $10.0 \mathrm{~s}^{-1}$. Two greatly different cooling rates of (a) $0.1{ }^{\circ} \mathrm{C} \cdot \mathrm{s}^{-1}$ and (b) $30.0{ }^{\circ} \mathrm{C} \cdot \mathrm{s}^{-1}$ were selected in order to clarify the effect of the cooling rate immediately before hot working on flow stress. After the compression test, the measured flow stresses were fitted by an approximate expression, and the microstructures were investigated by EBSD (Electron Back Scattered Diffraction Patterns).

Table 1 Chemical composition of specimen (mass \%)

\begin{tabular}{|c|c|c|c|c|c|c|c|c|}
\hline $\mathrm{C}$ & $\mathrm{Si}$ & $\mathrm{Mn}$ & $\mathrm{P}$ & $\mathrm{S}$ & $\mathrm{Ni}$ & $\mathrm{Cr}$ & $\mathrm{Mo}$ & $\mathrm{N}$ \\
\hline 0.03 & 0.3 & 0.7 & 0.03 & 0.005 & 7.0 & 24.6 & 2.5 & 0.080 \\
\hline
\end{tabular}

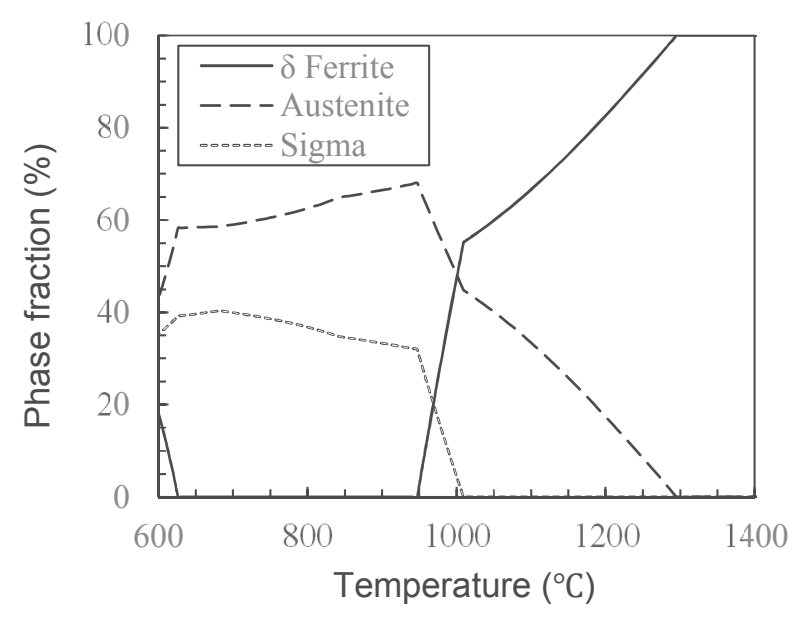

Figure 1 Equilibrium diagram of $25 \% \mathrm{Cr}$ steel

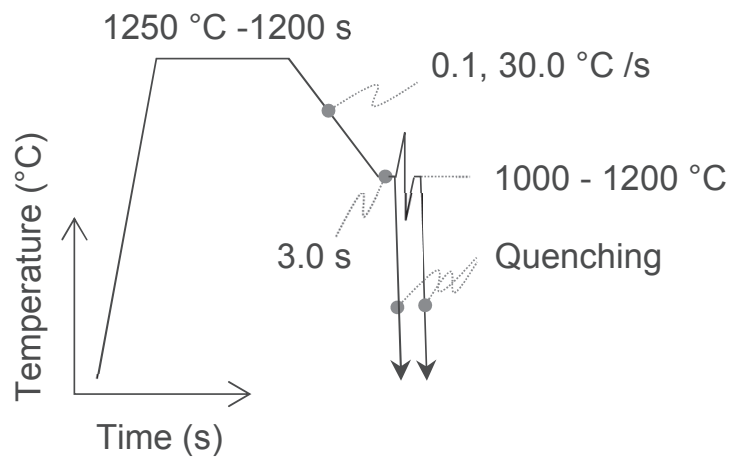

Figure 2 Thermal and hot working history 


\section{RESULTS AND DISCUSSION}

Figure 3 show the flow stress when cooling conditions (a) and (b) were used with the working temperature range of $1,000{ }^{\circ} \mathrm{C}$ to $1,200{ }^{\circ} \mathrm{C}$ and the strain rate of $1.0 \mathrm{~s}^{-1}$. The flow stresses changed depending on the conditions of cooling rates (a) and (b) immediately before hot working. Those flow stresses were fitted by equations (1) - (5) proposed by Yanagida [9]. The fitted coefficients are shown Table 2. The results of maximum flow stress $\sigma_{\max }$ and work-hardening exponent $n$ changed remarkably depending on the cooling rate immediately before hot working. Figure 4 shows the ratio of the austenite phase and its distribution just before hot working at $1,000{ }^{\circ} \mathrm{C}$. Under the condition of the rapid cooling rate (b), the supercooled $\delta$ ferrite phase just before hot working was maintained, and as a result, changes occurred in the strain distributions of the phases, which have different strengths, and the flow stress also changed.

$$
\begin{aligned}
& \bar{\sigma}=F_{1} \bar{\varepsilon}^{n} \\
& \bar{\sigma}=F_{2} \exp \left[a\left(\bar{\varepsilon}-\varepsilon_{\max }\right)^{2}\right]+F_{3} \quad\left(\bar{\varepsilon} \geqq \varepsilon_{c}\right) \\
& a=\frac{n F_{1} \varepsilon_{\mathrm{c}}^{n-1}}{2\left(\varepsilon_{\mathrm{c}}-\varepsilon_{\max }\right)\left(F_{1} \varepsilon_{\mathrm{c}}^{\mathrm{n}}-F_{3}\right)} \\
& F_{2}=\frac{F_{1} \varepsilon_{\mathrm{c}}^{n}-F_{3}}{\exp \left[a\left(\varepsilon_{\mathrm{c}}-\varepsilon_{\max }\right)^{2}\right]} \\
& \varepsilon_{\max }=\varepsilon_{\mathrm{c}}+\frac{F_{1} \varepsilon_{c}^{n}-F_{3}}{n F_{1} \varepsilon_{c}^{n-1}-(n-1) \varepsilon_{c}^{-1}\left(F_{1} \varepsilon_{c}^{n}-F_{3}\right)}
\end{aligned}
$$

where $\varepsilon_{c}(-)$ is critical strain for dynamic recrystallization, $F_{3}$ is steady sress (MPa) and $F_{1}, F_{2}, \alpha$ and $\varepsilon_{\max }$ are dependent parameters.

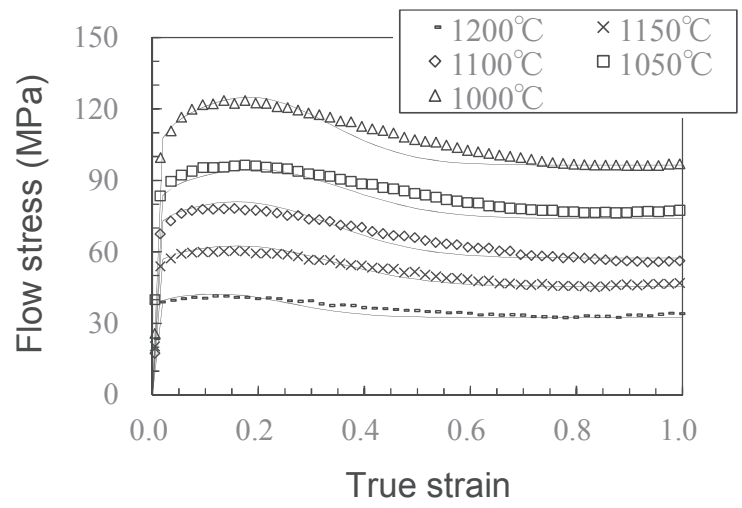

a) Cooling rate $0.1^{\circ} \mathrm{C} \cdot \mathrm{s}^{-1}$

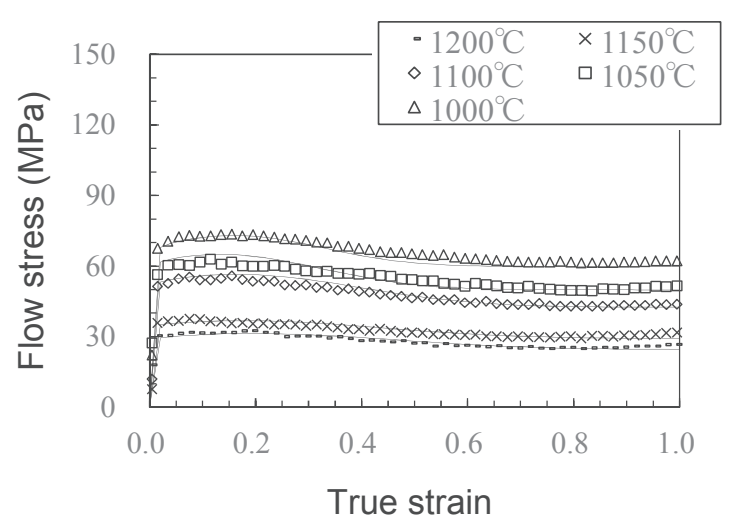

b) Cooling rate $30.0^{\circ} \mathrm{C} \cdot \mathrm{s}^{-1}$

Figure 3 Flow stresses with different cooling rates

Table 2 Fitted coefficients by equations (1) - (5)

\begin{tabular}{|c|c|c|c|c|c|c|c|c|c|c|}
\hline & \multicolumn{4}{|c|}{ (a) Cooling rate: $0.1^{\circ} \mathrm{C} \cdot \mathrm{s}^{-1}$} & \multicolumn{4}{|c|}{ (b) Cooling rate: $30.0^{\circ} \mathrm{C} \cdot \mathrm{s}^{-1}$} \\
\hline $\begin{array}{c}\text { Temperature } \\
\left({ }^{\circ} \mathrm{C}\right)\end{array}$ & $\begin{array}{c}F_{1} \\
(-)\end{array}$ & $\begin{array}{c}n \\
(-)\end{array}$ & $\begin{array}{c}\varepsilon_{\mathrm{c}} \\
(-)\end{array}$ & $\begin{array}{c}F_{3} \\
(\mathrm{MPa})\end{array}$ & $\begin{array}{c}\sigma_{\max } \\
(\mathrm{MPa})\end{array}$ & $\begin{array}{c}F_{1} \\
(-)\end{array}$ & $\begin{array}{c}n \\
(-)\end{array}$ & $\begin{array}{c}\varepsilon_{\mathrm{c}} \\
(-)\end{array}$ & $\begin{array}{c}F_{3} \\
(\mathrm{MPa})\end{array}$ & $\begin{array}{c}\sigma_{\max } \\
(\mathrm{MPa})\end{array}$ \\
\hline 1000 & 142.9 & 0.072 & 0.102 & 96.5 & 125.0 & 78.8 & 0.039 & 0.087 & 59.8 & 73.1 \\
\hline 1050 & 105.5 & 0.059 & 0.105 & 74.0 & 97.9 & 69.2 & 0.029 & 0.071 & 49.9 & 62.5 \\
\hline 1100 & 90.5 & 0.055 & 0.085 & 57.5 & 81.0 & 60.1 & 0.031 & 0.087 & 42.5 & 56.3 \\
\hline 1150 & 69.3 & 0.049 & 0.085 & 45.5 & 62.5 & 38.5 & 0.024 & 0.094 & 29.2 & 36.8 \\
\hline 1200 & 46.5 & 0.041 & 0.064 & 32.5 & 42.3 & 33.2 & 0.029 & 0.105 & 24.5 & 31.3 \\
\hline
\end{tabular}




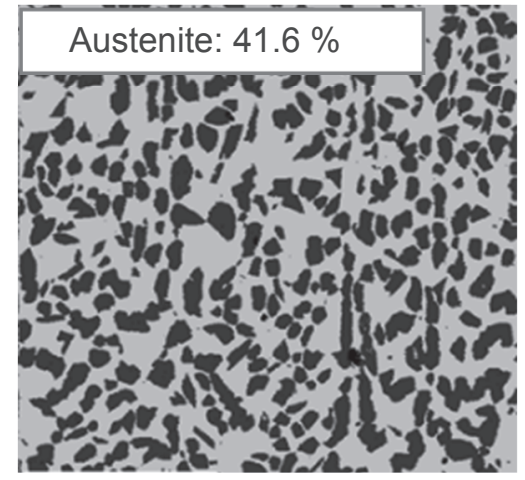

a) Cooling rate: $0.1^{\circ} \mathrm{C} \cdot \mathrm{s}^{-1}$

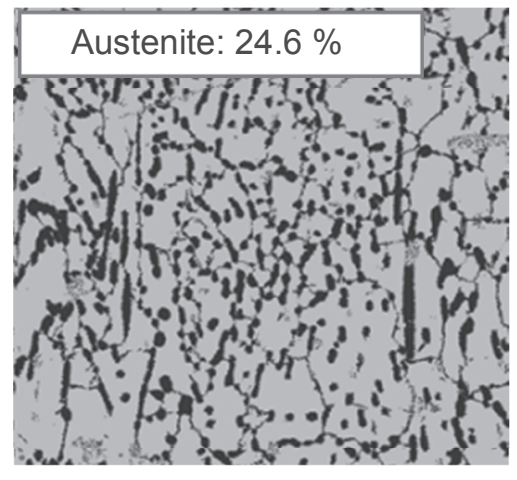

b) Cooling rate: $30.0^{\circ} \mathrm{C} \cdot \mathrm{s}^{-1}$

$300 \mu \mathrm{m}$

$\delta$ Ferrite

Austenite

Figure 4 Ratio of austenite phase and phase distribution just before hot working at $1,000{ }^{\circ} \mathrm{C}$

Figure 5 shows the flow stress with different strain rates. Under all strain rate conditions, $\sigma_{\max }$ of the rapid cooling condition (b) was lower than that of the slow cooling condition (a). These results were considered to reflect the influence of the supercooled $\delta$ ferrite phase. Another interesting characteristic was seen in the flow stress of cooling condition (b) with the low strain rate of $0.1 \mathrm{~s}^{-1}$. The stable stress $F_{3}$ of cooling condition (a) was a steady state, but $F_{3}$ of cooling condition (b) increased as strain increased. To investigate the mechanism of increased $F_{3}$ with increasing strain, the microstructure just after the compression test was observed by EBSD.

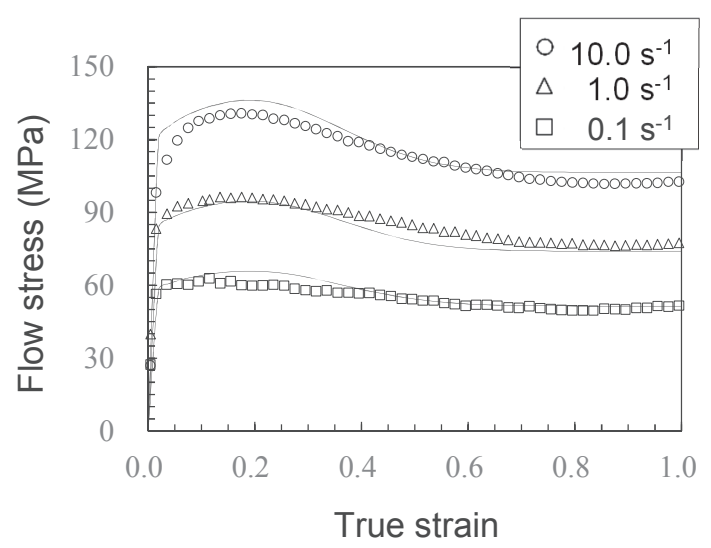

a) Cooling rate $0.1^{\circ} \mathrm{C} \cdot \mathrm{s}^{-1}$

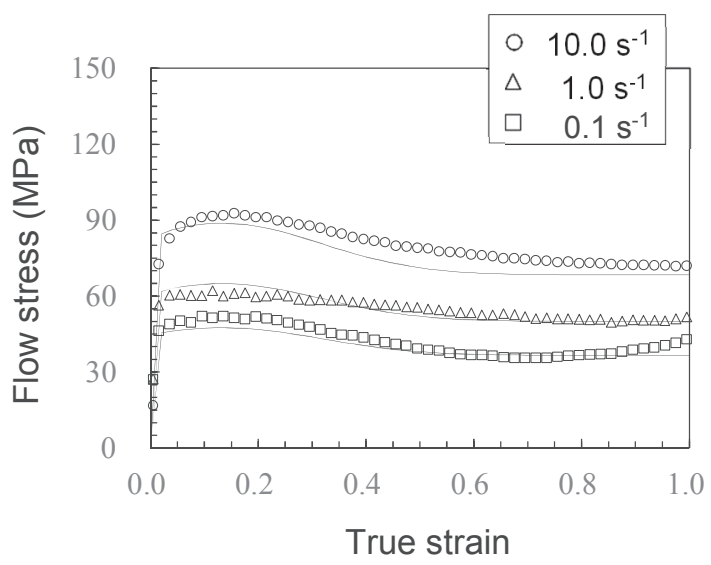

b) Cooling rate $30.0^{\circ} \mathrm{C} \cdot \mathrm{s}^{-1}$

Figure 5 Results of flow stress at $1,000{ }^{\circ} \mathrm{C}$ with different strain rates

Figure 6 shows the results of image quality and phase maps of the $\delta$ ferrite and austenite phase. Just before the compression test, the ratio of the austenite phase was only $24.6 \%$, as shown in Figure 4, by reason of the supercooled $\delta$ ferrite, as mentioned above. However, the compressed specimen shown in Figure 6 contained a large amount of austenite phase. From this result, under the condition of a slow strain rate with rapid cooling just before the hot compression test, it is thought that the austenite phase was transformed from the $\delta$ ferrite phase during hot compression testing. Figure 7 shows the result of inverse pole figure orientation mapping of the austenite phase. All of the transformed austenite grains had gradation; in other words, compression strain was introduced into the transformed austenite grains. S. Sasaki [10] reported the hot 
strength of each single phase of duplex stainless steel, and clarified the fact that the hot strength of the austenite phase is considerably higher than that of the $\delta$ ferrite phase. From those results, it is considered that, under the condition of rapid cooling just before working with a slow strain rate, the stable stress $F_{3}$ increased with increasing strain due to the transformed harder austenite phase generated during hot working. Summarizing the key point of these results, for accurate prediction of the working load and strain distribution when hot working is performed with a sudden temperature change, it is necessary to measure the flow stress considering the thermal history immediately before working.

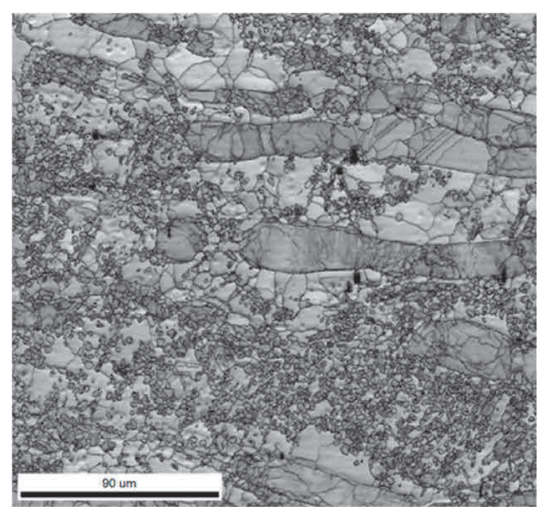

a) Image quality map

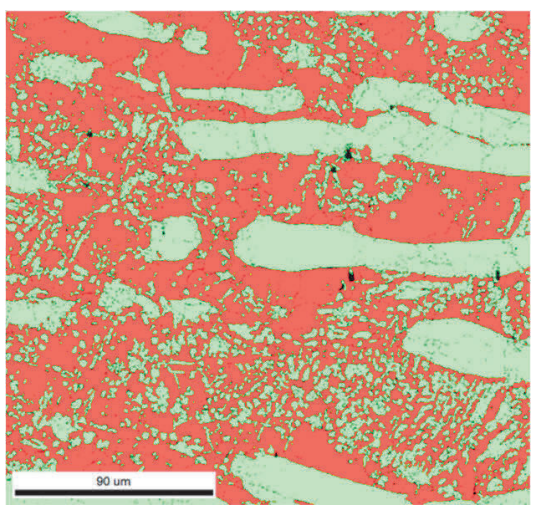

b) Phase map ( $\square \delta$ ferrite, $\square$ austenite); ratio of austenite phase: $44.5 \%$

Figure 6 Results of image quality and phase maps of $\delta$ ferrite and austenite phases - cooling rate: $30.0^{\circ} \mathrm{C} \cdot \mathrm{s}^{-1}$, strain rate: $0.1 \mathrm{~s}^{-1}$
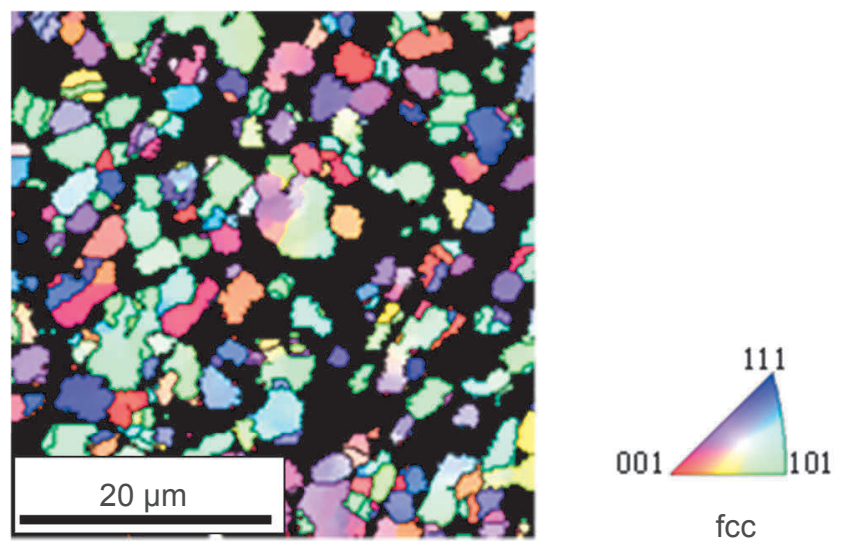

Figure 7 Result of inverse pole figure orientation mapping of austenite phase (black portion: $\delta$ ferrite) cooling rate: $30.0^{\circ} \mathrm{C} \cdot \mathrm{s}^{-1}$, strain rate: $0.1 \mathrm{~s}^{-1}$

\section{CONCLUSION}

The influence of the cooling rate immediately before hot working on the flow stress and microstructure in $25 \%$ $\mathrm{Cr} \delta$ ferrite-austenite duplex stainless steel was investigated. The cooling rates just before the hot compression test were 0.1 and $30.0^{\circ} \mathrm{C} \cdot \mathrm{s}^{-1}$, the test temperature range was $1,000{ }^{\circ} \mathrm{C}$ to $1,200{ }^{\circ} \mathrm{C}$, and the strain rate range was $0.1 \mathrm{~s}^{-1}$ to $10.0 \mathrm{~s}^{-1}$. The main conclusions of this study may be summarized as follows.

The condition of rapid cooling immediately before hot working resulted in a large decrease in the maximum flow stress $\sigma_{\max }$ and work hardening coefficient $n$ by reason of the larger volume fraction of the supercooled $\delta$ ferrite phase. 
Under the condition of a slow strain rate and rapid cooling just before the hot compression test, the supercooled $\delta$ ferrite phase produced by rapid cooling gradually transformed to the harder austenite phase during the slow hot compression test. As the result, stable stress was increased by the austenite transformation with increasing strain.

\section{REFERENCES}

[1] YANG, Y. and YAN, B. The microstructure and flow behavior of 2205 duplex stainless steels during high temperature compression deformation. Materials Science \& Engineering A. 2013. vol. 579, pp. 194-201.

[2] MOMENI, A., DEHGHANI, K., and ZHANG, X. X. Mechanical and microstructural analysis of 2205 duplex stainless steel under hot working condition. Journal of Materials Science. 2012. vol. 47, no. 6, pp. 2966-2974.

[3] FAN, G., W., LIU, J and QIAO, G., J. Hot ductility and microstructure in casted 2205 duplex stainless steels, Materials Science and Engineering A. 2009. vol. 515, pp. 108-112.

[4] FARNOUSH, H., MOMENI, A., DEHGHANI, K., MOHANDESI, A., and KESHMIRI, H. Hot deformation characteristics of 2205 duplex stainless steel based on the behavior of constituent phases. Materials and Design. 2010. vol. 31, pp. 220-226.

[5] KEARNS, J., R. The microstructure and properties of a duplex stainless steel as related to hot deformation, Microstructure Science. 1987. vol. 15, pp. 529-545.

[6] SPIGARELLI, S. Constitutive equations for prediction of the flow behavior of duplex stainless steel. Materials Science and Engineering A. 2010. vol. 527, pp. 4218-4228.

[7] MOREIRA, A. J. and OSCAR, B. Influence of the microstructure on the plastic behavior of duplex stainless stress, Materials Science and Engineering A. 2011. vol. 528, pp. 2259-2264.

[8] BARTERI, M. and MECOZZI, M., G. Hot workability of some duplex stainless steels. In: $4^{\text {th }}$ International Conference Duplex Stainless Steels, 1995, pp. 57-65.

[9] YANAGIDA, A., LIU, J., and YANAGIMOTO, J. Flow curve determination for metal under dynamic recrystallization using inverse analysis. Materials Transaction. 2003. vol. 44, no. 11, pp. 2303-2310.

[10] SASAKI, S., KATSUMURA, T. and OTA, H. Influence of thermal history before hot working on hot workability of multi-phase steel. In: ICTP 2017: International Conference on the Technology of Plasticity. Cambridge, United Kingdom: 17.-22. September 2017, pp. 1827-1832. 